DOI: 10.12731/2070-7568-2020-2-49-64

УДК 330.117

\title{
ОЦЕНКА ЭФФЕКТИВНОСТИ ДЕЯТЕЛЬНОСТИ ОРГАНОВ ГОСУДАРСТВЕННОЙ ВЛАСТИ И УПРАВЛЕНИЯ В РОССИИ
}

\author{
Герсонская И.В.
}

В статье проанализированы основные показатели деятельности органов государственной власти и управления в России. Bblявлены существенные проблемы, присущие российской системы государственного управления.

Цель работы - оценка эффективности деятельности органов государственной власти и управления в России на основе статистических данных.

Метод или методология проведения работы: общенаучные методы, приемы научной абстракции, наблюдения и системного исследования.

Результаты. Оиенка деятельности органов государственной власти и управления свидетельствует о довольно значительной численности чиновничьего аппарата и высоких расходах на государственное управление. В России на не высоком уровне находится развитие системы электронного правительства, что мешает в полной мере осуществлять онлайн-взаимодействие властных структур с предпринимательским сектором и домохозяйствами. Анализ индикаторов уровня жизни населения показал довольно низкие реальные доходы и существенное социальное расслоение российского общества, что отрицательно характеризуют функиионирование системы государственного управления.

Область применения результатов. Результаты проведенного исследования могут быть использованы органами государственной власти и управления в России для разработки критериев, направленных на повышение эффективности их деятельности и роста 
уровня жизни населения страны, а так же научными сотрудниками, изучающими проблематику в данной области.

Ключевые слова: государственное управление; численность; расходы;; электронное правительство; государственные услуги; уровень жизни.

\section{PERFORMANCE ASSESSMENT OF THE PUBLIC AUTHORITIES AND GOVERNANCE BODIES IN RUSSIA}

\section{Gersonskaya I.V.}

The article analyzes the main performance indicators of the public authorities and governance bodies in Russia as well as reveals significant problems inherent in the Russian system of public administration.

The purpose of the work is to assess the performance of the Russian public authorities and governance bodies based on statistical data.

Method or methodology of work: general scientific methods, techniques of scientific abstraction, observation and systemic research.

Results. Performance assessment of the public authorities and governance bodies reveals the fact that the bureaucracy in Russia is rather large and its functioning involves high expenditures. The e-government system is still far from being highly developed, which makes it difficult to fully implement online coordination of government structures with both the business sector and households. An analysis of the indicators of the population's living standards shows rather low real income levels and a significant social stratification of Russian society, which negatively characterizes the functioning of the public administration system.

Practical implications. The results of the study can be used by the Russian public authorities and governance bodies to develop criteria aimed at increasing their performance level and the standard of living of the country's population, as well as by researchers studying the problems in this area.

Keywords: public administration; number; expenditures; e-government; public services; standard of living. 


\section{Введение}

В современных условиях государство является основным регулятором системы национальной экономики, а эффективность функционирования системы государственного управления является залогом не только экономического роста в стране, но гарантом увеличения уровня жизни населения, всестороннего и гармоничного развития человеческого капитала, роста качества жизни всех социальных слоев и повышения степени общественного благополучия.

Эффективность или неэффективность государственного управления является актуальной проблемой во многих странах и на многих уровнях $[18$, с. 11]. Поэтому цель нашего научного исследования состоит в оценке основных показателей, характеризующих эффективность функционирования системы государственного управления в нашей стране. Задачами исследования являются изучение динамики численности работников органов государственной власти и местного самоуправления, управленческих расходов государства и их доли в ВВП, развития системы электронного правительства и предоставления государственных услуг, а также ключевых индикаторов уровня жизни населения.

Вопросам государственного управления в России посвящены научные труды многих отечественных ученых, в частности Е.А. Колесниченко, М.А. Мирошниченко, В.А. Мау, А.Н. Тереховой, А.Е. Хватова, Ю.Г. Швецова и др. Однако данная тема исследования еще долгое время будет оставаться актуальной для российского общества, а степень проработанности вопросов государственного управления еще далека от совершенства. При этом системе государственного управления в России присуще множество противоречий и нерешенных до настоящего времени проблем, что требует проведения новых научных изысканий.

\section{Материалы и методы исследования}

В качестве основы методологии научного исследования мы принимаем концепцию функционирования системы государственного управления, которая является основным экономическим регулятором в стране. Областью предлагаемого нами исследования служит 
деятельность органов государственной власти и управления в России. Информационной базой исследования являются официальные статистические материалы Росстата, научные издания Национального исследовательского университета «Высшая школа экономики» и Института экономической политики имени Е.Т. Гайдара, данные Аналитического центра при Правительстве РФ. Период исследования 2010-2018 годы. В процессе изучения деятельности системы государственного управления нами были использованы как общенаучные методы познания и системного исследования, так и традиционные приемы аналитического исследования, способы сравнения и группировок, статистические методы, горизонтальный и вертикальный анализ. При обосновании выводов и практических рекомендаций нами были использованы некоторые положения научных трудов Е.А. Аникиной, Л.И. Гавриленко, М.А. Мирошниченко, Е.А. Колесниченко, О.В. Рудаковой, А.В. Плахова, А.Н. Тереховой, А.Е. Хватова, А.С. Ваторопина, Ю.Г. Швецова [1, 2, 3, 4, 9, 10, 12$]$.

\section{Результаты исследования и их обсуждение}

Деятельность органов государственной власти и управления, а также эффективность их функционирования характеризируют многочисленные показатели. К ним можно отнести численность работников и производительность их труда, изменение организационной структуры системы государственного управления и расходов, связанных с ее функционированием, рациональность государственного регулирования национальной экономики и целевая эффективность управленческих решений, принимаемых на уровне государства, степень внедрения цифровых технологий в органы государственной власти и управления, качество оказываемых государственных услуг, индикаторы уровня жизни и качества населения, а также многие другие аналогичные показатели, характеризующие эффективность деятельность органов государственной власти и управления. В процессе научного исследования мы остановимся на существенных, по нашему мнению, индикаторах, а также показателях наиболее распространенных в официальных источниках информации, и прежде всего, в данных 
Росстата. К таким показателям мы отнесли численность работников органов государственной власти и управления, использование ВВП на нужды государственного управления, использование информационно-коммуникационных технологий и качество предоставления государственных услуг, индикаторы уровня жизни населения.

Сегодня «проблема оценки управленческого потенциала...становится актуальной... в сфере государственного и муниципального управления» [17, с. 296]. Поэтому на рисунке 1 приведем изменение численности работников органов государственной власти и управления в нашей стране за 2010-2018 годы.

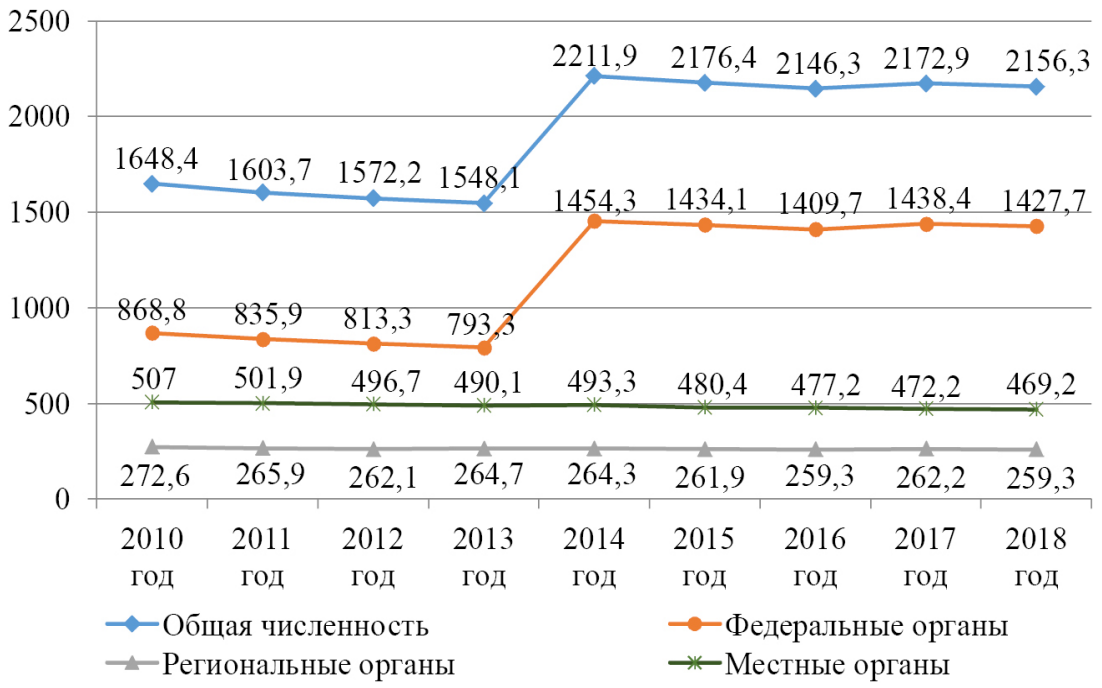

Источник: Составлено автором по данным Росстата [5, с. 62-63; 6, с. 58-59]

Рис. 1. Динамика численности работников органов государственной власти в РФ, тыс. чел.

Приведенные данные свидетельствуют, что до 2013 года в России численность работников имела тенденцию к сокращению. Однако в 2014 году произошел значительный рост государственных служащих на федеральном уровне. При этом их число существенно превысило численность служащих в субъектах РФ и органах местного самоуправления. Данный фактор свидетельствует об усилении 
процесса централизации государственной власти на федеральном уровне, и «на сегодняшний день в системе российского государственного управления следует констатировать высочайший уровень сосредоточения власти в руках чиновников и узкой группы элит, провоцирующих коррупцию, неравенство и отсталость» [3, с. 166]. Рост численности работников всегда связан и с увеличением управленческих расходов государства, поэтому в таблице 1 приведем динамику использования ВВП на нужды государственного управления, а также расходов домохозяйств, поскольку «долю потребления в ВВП страны можно считать одним из важных индикаторов благосостояния населения. Как правило, в развитых странах норма потребления выше, чем в развивающихся» [13, с. 3].

Таблицуа 1. Динамика использования ВВП в Российской Федерации за 2010-2018 годы

\begin{tabular}{|l|c|c|c|c|c|c|c|c|c|}
\hline \multicolumn{1}{|c|}{ Показатели } & $\begin{array}{c}2010 \\
\text { год }\end{array}$ & $\begin{array}{c}2011 \\
\text { год }\end{array}$ & $\begin{array}{c}2012 \\
\text { год }\end{array}$ & $\begin{array}{c}2013 \\
\text { год }\end{array}$ & $\begin{array}{c}2014 \\
\text { год }\end{array}$ & $\begin{array}{c}2015 \\
\text { год }\end{array}$ & $\begin{array}{c}2016 \\
\text { год }\end{array}$ & $\begin{array}{c}2017 \\
\text { год }\end{array}$ & $\begin{array}{c}2018 \\
\text { год }\end{array}$ \\
\hline $\begin{array}{l}\text { 1. ВВП, млрд. руб., } \\
\text { в т.ч. расходы: }\end{array}$ & 46309 & 55967 & 62218 & 66755 & 79058 & 83094 & 86014 & 92101 & 103876 \\
\hline $\begin{array}{l}\text { 2. Расходы домохо- } \\
\text { зяйств, млрд. руб. }\end{array}$ & 23617 & 27192 & 30831 & 34399 & 41955 & 43242 & 45317 & 48136 & 50851 \\
\hline $\begin{array}{l}\text { 3. Расходы на госу- } \\
\text { дарственное управ- } \\
\text { ление, млрд. руб.: }\end{array}$ & 8671 & 10103 & 11889 & 13048 & 14173 & 14684 & 15729 & 16649 & 18049 \\
\hline $\begin{array}{l}\text { - на индивиду- } \\
\text { альные товары, } \\
\text { услуги }\end{array}$ & 4118 & 4850 & 5384 & 5776 & 6177 & 6408 & 6565 & 6820 & 7654 \\
\hline $\begin{array}{l}\text { - на коллективные } \\
\text { услуги }\end{array}$ & 4553 & 5253 & 6505 & 7272 & 7996 & 8276 & 9164 & 9829 & 10395 \\
\hline $\begin{array}{l}\text { 4. Расходы домохо- } \\
\text { зяйств в ВВП, \% }\end{array}$ & 50,5 & 48,4 & 49,1 & 51,6 & 52,9 & 51,7 & 52,8 & 52,2 & 49,2 \\
\hline $\begin{array}{l}\text { 5. Расходы на госу- } \\
\text { дарственное управ- } \\
\text { ление в ВВП, \% }\end{array}$ & 18,5 & 18,0 & 19,0 & 19,6 & 17,9 & 17,6 & 18,2 & 18,1 & 17,5 \\
\hline $\begin{array}{l}\text { - на индивидуаль- } \\
\text { ные товары, услуги }\end{array}$ & 8,8 & 8,7 & 8,6 & 8,7 & 7,8 & 7,7 & 7,6 & 7,4 & 7,4 \\
\hline $\begin{array}{l}\text { - на коллективные } \\
\text { услуги }\end{array}$ & 9,7 & 9,3 & 10,4 & 10,9 & 10,1 & 9,9 & 10,6 & 10,7 & 10,1 \\
\hline
\end{tabular}

Источник: Составлено автором по данным Росстата [5, с. 191-192; 6, c. 195-196]. 
По данным таблицы 1 видно, что ВВП нашей страны имеет устойчивую тенденцию к росту, то есть «налицо экономический рост, однако его темп, существенно отстающий от среднемирового...2,3\%» [8, c. 25]. При этом расходы домохозяйств в ВВП не слишком велики и имеют тенденцию к снижению до 49,2\%, что негативно характеризует уровень общественного благосостояния, поскольку «доля потребления в мировом валовом выпуске в 2017 году составила 57,9\%...В странах «Группы двадцати» этот показатель оказался немного ниже среднемирового уровня - 57,2\% ВВП в 2017 году (56,9\% в 2018 году...)» [13, c. 3]. Поэтому, мы полагаем, что использование ВВП на государственное управление в 17,5\% для России является еще довольно высоким, а его использование на индивидуальные товары и услуги снизилось до 7,4\%, тогда как на коллективные услуги повысилось до 10,1\%. По нашему мнению, данные факторы во многом свидетельствуют не только о нерациональном использовании ВВП, но и существенном завышении расходов на государственное управление.

Следующий, довольно существенный показатель, характеризующий деятельность органов государственной власти и управления, по нашему мнению, является уровень цифровизации государственного управления. Данный показатель свидетельствует об использовании цифровых технологий, развитии системы электронного правительства, онлайн-взаимодействия властных структур с населением и предпринимательским сектором. В таблице 2 приведем данные по использованию информационно-коммуникационных технологий в России.

Таблицуа 2.

Использование ИКТ в органах государственного управления в РФ за 2017-2018 годы

\begin{tabular}{|c|c|c|c|c|c|c|c|}
\hline \multirow{2}{*}{$\begin{array}{c}\text { Органы го- } \\
\text { сударствен- } \\
\text { ной власти } \\
\text { и управле- } \\
\text { ния }\end{array}$} & \multicolumn{6}{|c|}{ Организации, использовавшие } & \multirow{2}{*}{$\begin{array}{c}\text { Органи- } \\
\text { зации, } \\
\text { имевшие } \\
\text { Web- } \\
\text { сайт }\end{array}$} \\
\hline & $\begin{array}{c}\text { персо- } \\
\text { нальные } \\
\text { компью- } \\
\text { теры }\end{array}$ & $\begin{array}{c}\text { сер- } \\
\text { веры }\end{array}$ & $\begin{array}{c}\text { локальные } \\
\text { вычисли- } \\
\text { тельные } \\
\text { сети }\end{array}$ & $\begin{array}{l}\text { сеть } \\
\text { Ин- } \\
\text { тер- } \\
\text { нет }\end{array}$ & $\begin{array}{c}\text { в т.ч. ши- } \\
\text { рокопо- } \\
\text { лосный } \\
\text { доступ }\end{array}$ & $\begin{array}{c}\text { «облач- } \\
\text { ные» } \\
\text { серви- } \\
\text { сы }\end{array}$ & \\
\hline За 2017 год & & 46,3 & & 94,6 & & & \\
\hline За 2018 год & 97,2 & 47,2 & 62,4 & 94,7 & 87,9 & 22,7 & 47,9 \\
\hline
\end{tabular}

Источник: Составлено автором по данным Росстата [6, с. 380; 7, с. 427]. 
Как свидетельствуют приведенные в таблице 2 данные, уровень использования цифровых технологий в органах государственной власти и управления не высок. В 2018 году веб-сайты имели всего 47,9\% правительственных учреждений, облачные сервисы использовали - 22,7\%, а серверы - 47,2\%. Эти факторы во многом затрудняют развитие электронного правительства в России, которое имеет в настоящее время «...все необходимые базовые компоненты такой системы управления: единый электронный портал государственных услуг; единый электронный портал государственных закупок; государственный электронный информационный центр; развитие сети многофункциональных центров в стране; центры общественного доступа к информации и различные типы колл-центров; система межведомственного электронного взаимодействия субъектов государственного сектора и др.» [15, с. 229]. Однако индекс развития электронного правительства в России в 2018 году составил всего 0,9167, что соответствует 32-му месту [11, с. 58], тогда как в экономически развитых странах аналогичный показатель намного выше. В частности, Дания имеет индекс развития электронного правительства в 1,0, Республика Корея и Великобритания - 0,9792, Швеция 0,9444, Финляндия - 0,9653, Франция - 0,9792, Япония - 0,9514 $[11$, с. 58]. Так же в России довольно низкое онлайн-взаимодействие органов государственной власти и управления с гражданами и бизнесом. Такое взаимодействие осуществляют только 33\% [11, c. 59] населения страны и 66,6\% [11, с. 64] субъектов предпринимательского сектора, тогда как у мировых лидеров и эти показатели выше. Кроме того, к проблемам, которые препятствуют оказанию государственных услуг в электронной форме в нашей стране является «...отсутствие широкополосного доступа в Интернет в малых населенных пунктах, необходимость личного визита с оригиналами некоторых документов в орган власти (даже в случае подачи заявления с портала госуслуг), нет возможности бесплатного получения электронных подписей, хотя бы для социально незащищенных категорий граждан» [10, с. 56]. При этом, несмотря на определенные трудности, связанные с процессами цифровизации органов государ- 
ственной власти и управления, в нашей стране оказываются довольно качественные государственные услуги населению и бизнесу, в том числе предоставляемые в электронной форме. В частности, «... за 2014-2016 гг. текущее состояние работы МФЦ оценивается как хорошее» [4, с. 1667-1668], а «...на момент 2018 года большинство потребителей государственных (муниципальных) услуг довольны качеством работы органов государственной власти» [9, с. 324].

Следующими, не менее значимыми показателями, характеризующими деятельности органов государственной власти и управления, являются индикаторы уровня жизни населения страны. Только на государственном уровне устанавливаются такие важнейшие социальные нормативы, как минимальный размер оплаты труда и величина прожиточного минимума, поскольку «в современном мире общественное мнение...интересы работодателей противоположны» [16, с. 892]. На рисунке 2 покажем динамику индикаторов уровня жизни.

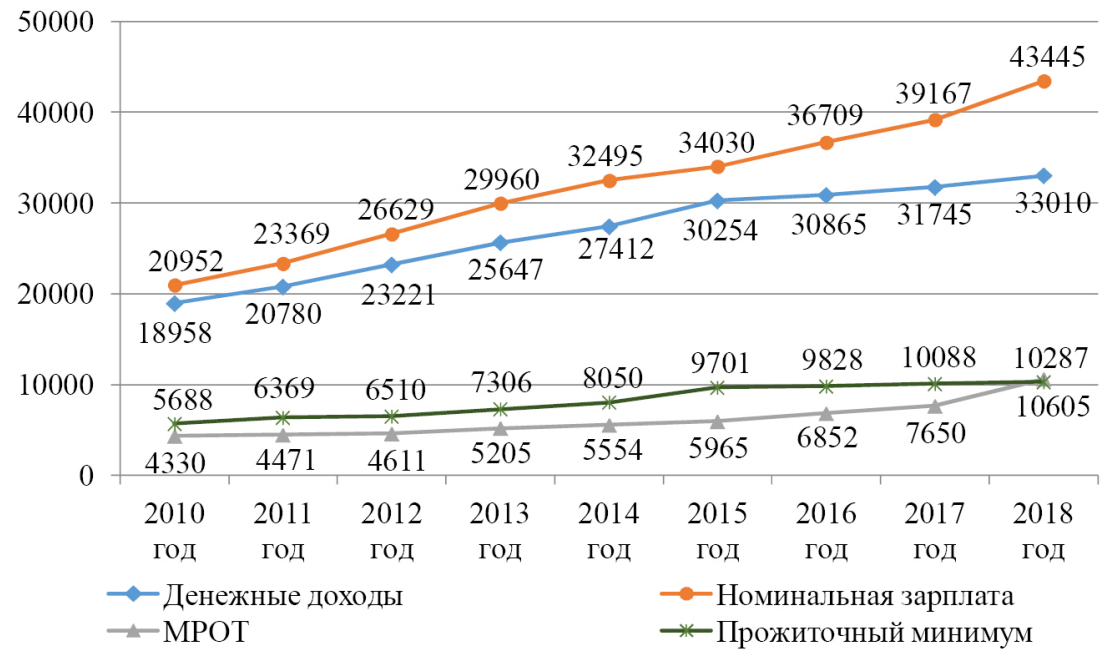

Источник: Составлено автором по данным Росстата [5, с. 127-130; 6, с. 113-116]

Рис. 2. Динамика денежных доходов населения в РФ за 2010-2018 годы, руб.

На рисунке 2 отчетливо видна положительная динамика роста доходов населения России. За 2010-2018 год в абсолютном выра- 
жении выросли среднедушевые денежные доходы и номинальная заработная плата. Однако до 2018 года наблюдалось превышение прожиточного минимума над минимально установленной государством оплатой труда, что оказывало довольно негативное влияние на рост уровня общественного благосостояния. Также после нового витка экономического кризиса 2014-2015 годов происходило фактическое падение денежных доходов населения и только в 2018 году «...pеальные располагаемые доходы населения впервые за 5 лет продемонстрировали рост...на 0,1\%...» [2, с. 3]. Поэтому в нашей стране показатели, характеризующие реальный уровень жизни населения не высокие, а «в 2018 г. доля субъективно бедного населения, оценивающего свое материальное положение как «плохое» или «очень плохое», составила 23-26\%...» [8, с. 338]. В целях подтверждения сделанных выводов, в таблице 3 приведем индикаторы уровня жизни населения.

Таблицуа 3.

Динамика основных показателей уровня жизни населения в РФ за 2010-2018 годы

\begin{tabular}{|l|c|c|c|c|c|c|c|c|c|}
\hline \multicolumn{1}{|c|}{ Показатели } & $\begin{array}{c}2010 \\
\text { год }\end{array}$ & $\begin{array}{c}2011 \\
\text { год }\end{array}$ & $\begin{array}{c}2012 \\
\text { год }\end{array}$ & $\begin{array}{c}2013 \\
\text { год }\end{array}$ & $\begin{array}{c}2014 \\
\text { год }\end{array}$ & $\begin{array}{c}2015 \\
\text { год }\end{array}$ & $\begin{array}{c}2016 \\
\text { год }\end{array}$ & $\begin{array}{c}2017 \\
\text { год }\end{array}$ & $\begin{array}{c}2018 \\
\text { год }\end{array}$ \\
\hline $\begin{array}{l}\text { 1. Реальные располагаемые } \\
\text { денежные доходы, в \% к } \\
\text { предыдущему году }\end{array}$ & 106 & 100 & 105 & 103 & 99 & 98 & 96 & 99 & 100 \\
\hline 2. Уровень безработицы, \% & 7,3 & 6,5 & 5,5 & 5,5 & 5,2 & 5,6 & 5,5 & 5,2 & 4,8 \\
\hline $\begin{array}{l}\text { 3. Население с доходами } \\
\text { ниже прожиточного мини- } \\
\text { мума, млн. чел. }\end{array}$ & 17,7 & 17,9 & 15,4 & 15,7 & 16,1 & 19,5 & 19,5 & 19,3 & 18,9 \\
\hline $\begin{array}{l}\text { - в \% от численности на- } \\
\text { селения }\end{array}$ & 12,5 & 12,7 & 10,7 & 11,0 & 11,2 & 13,3 & 13,3 & 13,2 & 12,9 \\
\hline $\begin{array}{l}\text { 4. Коэффициент фондов, в } \\
\text { разах }\end{array}$ & 16,6 & 16,2 & 16,4 & 16,2 & 16,0 & 15,7 & 15,5 & 15,3 & 15,5 \\
\hline 5. Коэффициент Джини & 0,421 & 0,417 & 0,420 & 0,418 & 0,416 & 0,413 & 0,412 & 0,409 & 0,411 \\
\hline
\end{tabular}

Источник: Составлено автором по данным Росстата [5, с. 102, 127-130, 139; 6, с. 87, 113-116, 126].

Данные, приведенные в таблице 3, характеризует падение реальных располагаемых доходов на протяжении 2014-2017 годов. В России практически ежегодно увеличивается население с до- 
ходами ниже прожиточного минимума, которое к концу 2018 года уже составило 18,9 млн. чел. или $12,9 \%$ от общей численности. При этом «десятки миллионов россиян живут все беднее и беднее, но заботиться о них на государственном уровне абсолютно некому» [12, с. 317]. Уровень безработицы постепенно снижается, что, безусловно, является положительным фактором, однако в России население, которое официально не может трудоустроиться, составляет еще 4,8\%. Также российскому обществу характерно сильное социальное расслоение, а «...бедные тратят меньше на продовольствие, здравоохранение и образование...» [14, с. 280], что существенно снижает качество их жизни. На этот факт указывают и коэффициенты дифференциации доходов. К 2018 году коэффициент фондов еще довольно высок, хотя несколько снизился до 15,5 раз. Коэффициент Джини также понизился до 0,411, но это лишь «...свидетельствует о незначительном снижении неравенства доходов населения» [2, с. 11]. Однако значение индекса Джинии еще довольно высоко, так как его «...нормальное значение находится в пределах 0,25-0,3» [1, с. 247]. Поэтому можно сделать вывод, что социальное расслоение в российском обществе находится на очень высоком уровне, а разрыв между богатыми и бедными слоями очень велик, что отрицательно характеризует деятельность органов государственной власти и управления, которые должны являться гарантом повышения уровня общественного благосостояния.

\section{Заключение}

В процессе проведения научного исследования нами установлено, что показатели деятельности органов государственной власти, и прежде всего, существенные для российского общества в целом, свидетельствуют о довольно значительных проблемах, присущих всей системе государственного управления в нашей стране. К таким проблемам, по нашему мнению, можно отнести:

Во-первых, большой чиновничий аппарат, который не только приводит к серьезным проволочкам в процессе принятия управлен- 
ческих решений на государственном уровне, усилению бюрократии и снижении степени доверия населения к правительственным структурам, но и к быстрому росту государственных расходов на его содержание, которые ежегодно увеличиваются.

Во-вторых, нерациональное использование ВВП, поскольку в его составе расходы на государственное управление занимают существенный удельный вес и характеризуются повышением доли на коллективные услуги, тогда как доля ВВП, использованная на индивидуальные товары и услуги, снижается.

В-третьих, не достаточный уровень цифровизации, развития электронного правительства и степени онлайн-взаимодействия государственных структур с предпринимательским сектором и домохозяйствами. Дальнейшее внедрение цифровых технологий не только снизить численность чиновников и сократить государственные расходы, но и приведет к уменьшению бюрократии.

В-четвертых, довольно низкий уровень жизни населения нашей страны и высокая степень социального расслоения в российском обществе. Мы полагаем, что решение именно этой проблемы имеет первостепенное значение, поскольку важные социальные нормативы устанавливаются государством, что и оказывает непосредственное влияние на уровень и качество жизни населения.

Таким образом, деятельность органов государственной власти и управления оказывает существенное влияние на социально-экономическое развитие страны. При этом в современных условиях главным должен стать не просто экономический рост, который характеризуется положительной динамикой основных макроэкономических показателей, и прежде всего, ВВП, а его социально-ориентирующая составляющая - всестороннее развитие человеческого капитала, повышение уровня и качества жизни населения, рост общественного благосостояния. При соблюдении этих условий экономический рост становится инклюзивным, обеспечивает действие принципов социальной справедливости и ориентируется на потребности каждого члена общества. И именно на достижение этих целей должно быть направлено функционирование государства. 


\section{Список литературы}

1. Аникина Е.А., Гавриленко Л.И. Экономическая теория: учебник. Томск: Изд-во Томского политехнического университета, 2014. 413 с.

2. Динамика доходов населения / Авт. кол. под рук. Л. Григорьева. М.: Аналитический центр при Правительстве РФ, вып. № 58, 2020. 16 с.

3. Колесниченко Е.А., Рудакова О.В., Плахов А.В. Эффективность государственного управления: Россия на фоне мировых тенденций // Среднерусский вестник общественных наук. 2018. Том 13. № 2. C. 161-175.

4. Мирошниченко М.А. Развитие системы предоставления электронных государственных и муниципальных услуг с применением мультирегиональности // Научный журнал КубГАУ. 2017. № 131(07). C. $1665-1675$.

5. Россия в цифрах. 2014: Краткий стат. сборник. М.: Росстат, 2014. $558 \mathrm{c.}$

6. Россия в цифрах. 2019: Краткий стат. сборник. М.: Буки Веди, 2019. 549 c.

7. Россия в цифрах. 2020: Краткий стат. сборник. М.: Буки Веди, 2020. $550 \mathrm{c}$.

8. Российская экономика в 2018 году / В. Мау и др.; науч. ред. А.Л. Кудрин, С.Г. Синельников-Мурылев. М.: Изд-во Ин-та Гайдара, 2019. $656 \mathrm{c}$.

9. Терехова А.Н. Оценка качества предоставляемых государственных (муниципальных) услуг // Инновационная экономика: перспективы развития и совершенствования. 2018. № 8(34). С. 320-327.

10. Хватов А.Е., Ваторопин А.С. Факторы, препятствующие получению населением государственных услуг в электронной форме // Вопросы управления. 2017. № 3(46). С. 53-61.

11. Цифровая экономика: 2019: краткий стат. сборник / Г.И. Абдрахманова, К.О. Вишневский, Л.М. Гохберг и др. М.: НИУ ВШЭ, 2019. $96 \mathrm{c}$.

12. Швецов Ю.Г. О бюрократическом государстве и экономике // Вестник Томского государственного университета. Экономика. 2018. № 44. C. 305-324. 
13. Экономика совместного потребления как новая экономическая модель / Авт. кол. под рук. Л. Григорьева. М.: Аналитический центр при Правительстве РФ, вып. № 47, 2019. 19 с.

14. Cojanu S., Stroe C. Nudges for poverty reduction // 47th International Scientific Conference on Economic and Social Development (Prague 2019), pp. 276-284.

15. Gersonskaya I. Leading Role of the Public Sector in the Digitalisation of Economy // 5th International Conference on Social, Economic, and Academic Leadership (ICSEALV 2019). Advances in Social Science, Education and Humanities Research. 2019. Vol. 386, pp. 228-234.

16. Goncharenko O., Holiuk O., Liganenko I., Frum O., Kostyrko A., Tkachuk T. Improving Staff Stimulation Systems: Causal-Consequence Approach // International Journal of Engineering and Advanced Technology. 2019. Vol. 8. № 5, pp. 891-894.

17. Sinyagin Yury V. The Components of Managerial Alacrity of Government Executives // European Research Studies Journal. 2018. Vol. XXI. № 1, pp. 295-308.

18. Vavrek R. Efficiency and inefficiency of public administration // Journal of Economic Development, Environment and People. 2018. Vol.7. № 1, pp. 6-14.

\section{References}

1. Anikina E.A., Gavrilenko L.I. Ekonomicheskaya teoriya [Economic theory]. Tomsk: Izd-vo Tomskogo politekhnicheskogo universiteta, 2014. $413 \mathrm{p}$.

2. Dinamika dokhodov naseleniya [Dynamics of incomes of the population] / Ed. L. Grigor'ev. M.: Analiticheskiy tsentr pri Pravitel'stve RF, № 58, 2020. 16 p.

3. Kolesnichenko E.A., Rudakova O.V., Plakhov A.V. Srednerusskiy vestnik obshchestvennykh nauk. 2018. V. 13. № 2, pp. 161-175.

4. Miroshnichenko M.A. Nauchnyy zhurnal KubGAU. 2017. № 131(07), pp. 1665-1675.

5. Rossiya $v$ tsifrakh [Russia in numbers]. 2014: Kratkiy stat. sbornik. M.: Rosstat, 2014. 558 p. 
6. Rossiya v tsifrakh [Russia in numbers]. 2019: Kratkiy stat. sbornik. M.: Buki Vedi, 2019. 549 p.

7. Rossiya $v$ tsifrakh [Russia in numbers]. 2020: Kratkiy stat. sbornik. M.: Buki Vedi, 2020. 550 p.

8. Rossiyskaya ekonomika v 2018 godu [Russian economy in 2018] / V. Mau et al.; ed. A.L. Kudrin, S.G. Sinel'nikov-Murylev. M.: Izd-vo In-ta Gaydara, 2019. 656 p.

9. Terekhova A.N. Innovatsionnaya ekonomika: perspektivy razvitiya $i$ so-vershenstvovaniya. 2018. № 8(34). S. 320-327.

10. Khvatov A.E., Vatoropin A.S. Voprosy upravleniya. 2017. № 3(46), pp. 53-61.

11. Tsifrovaya ekonomika: 2019 [Digital Economy: 2019]: kratkiy stat. sbornik / G.I. Abdrakhmanova, K.O. Vishnevskiy, L.M. Gokhberg et al. M.: NIU VShE, 2019. 96 p.

12. Shvetsov Yu.G. Vestnik Tomskogo gosudarstvennogo universiteta. Ekonomika. 2018. № 44, pp. 305-324.

13. Ekonomika sovmestnogo potrebleniya kak novaya ekonomicheskaya model' [The sharing economy as a new economic model] / Ed. L. Grigor'ev. M.: Analiticheskiy tsentr pri Pravitel'stve RF, № 47, 2019. 19 p.

14. Cojanu S., Stroe C. Nudges for poverty reduction. 47th International Scientific Conference on Economic and Social Development (Prague 2019), pp. 276-284.

15. Gersonskaya I. Leading Role of the Public Sector in the Digitalisation of Economy. 5th International Conference on Social, Economic, and Academic Leadership (ICSEALV 2019). Advances in Social Science, Education and Humanities Research. 2019. Vol. 386, pp. 228-234.

16. Goncharenko O., Holiuk O., Liganenko I., Frum O., Kostyrko A., Tkachuk T. Improving Staff Stimulation Systems: Causal-Consequence Approach. International Journal of Engineering and Advanced Technology. 2019. Vol. 8. № 5, pp. 891-894.

17. Sinyagin Yury V. The Components of Managerial Alacrity of Government Executives. European Research Studies Journal. 2018. Vol. XXI. № 1, pp. 295-308.

18. Vavrek R. Efficiency and inefficiency of public administration. Journal of Eco-nomic Development, Environment and People. 2018. Vol.7. № 1, pp. 6-14. 


\section{ДАННЫЕ ОБ АВТОРЕ}

Герсонская Ирина Валерьевна, доцент кафедры «Экономика и финансы», кандидат экономических наук, доцент

Российская академия народного хозяйства и государственной службы при Президенте РФ, Липеикий филиал

ул. Интернациональная, 3, г. Липецк, 398050, Российская Федерачия

g3071971@ya.ru

\section{DATA ABOUT THE AUTHOR}

Gersonskaya Irina Valeryevna, Associate Professor of the Department of Economics and Finance, Candidate of Economic Sciences, Associate Professor

Russian presidential Academy of national economy and public administration, Lipetsk branch

3, Internatsionalnaya Str., Lipetsk, 398050, Russian Federation g3071971@ya.ru 